\title{
Teatro "Brasileiro" nas Décadas de 1960-70: Regionalismo na cena amazônica paraense como lugar de resistência a tempos de ditadura
}

\author{
José Denis de Oliveira Bezerra \\ Universidade Federal do Pará - UFPA, Belém/PA, Brasil \\ E-mail: denisletras@yahoo.com.br
}

\section{Resumo}

Este artigo reflete sobre os sentidos do discurso regionalista no teatro paraense das décadas de 1960 e 70. São questões e direcionamentos apontados a partir do projeto de pesquisa Teatro em Belém: poéticas, memórias e militâncias (1964-1992), que visa investigar a relação entre a produção teatral na capital paraense durante regimes políticos autoritários e em momentos "democráticos". Com base nisso, esse texto parte da discussão de Ridenti (2000; 2005) sobre a produção cultural brasileira dessas duas décadas no contexto das disputas políticas entre o Estado ditatorial e o movimento de esquerda, liderado, principalmente, por artistas e intelectuais engajados a essa ideologia. Por isso, quer-se analisar os significados dos trabalhos cênicos de dramaturgos, como Nazareno Tourinho, e grupos com o que eles definiam ou procuravam representar como cultura amazônica/paraense.

\section{Palavras-chave}

Amazônia paraense. Nazareno Tourinho.

Regionalismo. Teatro.
This article proposes a reflection around the meanings of the regionalist discourse in the paraense theatre in the 1960s and 1970s. These are questions and directions raised from the research project Theatre in Belém: Poetics, Memory and Militancy (1964-1992), which aims to investigate the relationship between theatrical production in the State of Pará's capital during authoritarian political regimes and in the "democratic" moments. This text starts from the Ridenti $(2000 ; 2005)$ discussion on the Brazilian cultural production of these two decades in the context of the political disputes between the dictatorial state and the left-wing movement, led, mainly, by artists and intellectuals engaged in this ideology. We intend to compare the meanings of playwrights, such as Nazareno Tourinho, and groups works with what they had defined or tried to represent as Amazonian/paraense culture.

Pará's Amazon. Nazareno Tourinho.

Regionalism. Theater. 
Escrever sobre a relação do teatro com a sociedade, principalmente tendo como foco questões que perpassam conflitos ideológicos e políticos, possibilita a compreensão de como artistas das artes cênicas trabalham suas criações a partir dessas dimensões, em determinados momentos da história. Tais análises permitem a leitura dos sentidos da produção teatral no passado, no contexto em questão ou no diálogo entre o presente e o tempo histórico investigado. Dessa maneira, podem-se analisar as obras de arte como lugar de resistência, de luta ou de posicionamentos político-sociais contra tempos não democráticos.

Com base nessas questões, procura-se analisar a produção teatral em Belém do Pará na década de 1960-70, fazendo uma reflexão sobre os significados de pensamento e da criação teatral na capital paraense durante a ditadura militar. Para isso, tomamos como diálogo teórico os escritos de Ridenti (2000; 2005), ao refletir sobre o movimento cultural brasileiro dos anos 1960 e 70 em conversação com as formas de "resistência" da esquerda e a ideia de nacionalismo romântico.

Contudo, essa ideia de nacionalismo, defendida por Ridenti (2000; 2005), será contextualizada para o conceito de regionalismo como lugar de resistência à cultura não democrática do período, porque pretendemos mostrar como os artistas e as obras teatrais, na Amazônia paraense, em especial Belém, tomaram para si as práticas culturais locais como forma de posicionamento político, como lugar para representar as raízes culturais amazônicas.

Por isso, tomaremos como fonte documental a produção escrita, dramatúrgica e crítica, de Nazareno Tourinho (1934-2018), um dos mais produtivos escritores dramáticos da contemporaneidade, e que na década de 1960 e 70 escreveu peças teatrais que partiram do princípio da necessidade de falar dos elementos culturais paraenses. Somado a isso, dialogaremos com os pensamentos de Márcio Souza (1984), o qual promove uma interessante análise sobre o regionalismo no teatro manauara dos anos 70 .

Destaca-se, ainda, que toda vez que se propõe análises sobre fazeres artísticos no Brasil, quando está em foco a produção fora do eixo Rio - São Paulo, o conceito de regional é sempre colocado em questão. Em muitos casos e em determinados momentos históricos, os sentidos de valorização e de trabalho com as práticas culturais determinadas como regionais são recebidas e vistas de maneiras diversas. Ora como lugar de resistência e luta contra culturas hegemônicas, ora como um lugar que artistas precisam distanciar-se para alcançar um determinado reconhecimento, perante suas comunidades, e ter acesso aos ciclos culturais considerados como aqueles que reconhecem ou não obras e seus criadores.

\section{0 regionalismo no teatro: resistência em momentos não democráticos}

\section{AAmazônia paraense do século XX presenciou} diferentes movimentos culturais preocupados com a produção teatral na capital do estado. Durante boa parte desse século, grupos, artistas, dramaturgos, críticos e intelectuais se movimentaram em direção à transformação das formas e discursos, por meio de obras e articulações políticas, em prol do teatro local ${ }^{1}$. Ora buscando conexões com outros centros nacionais e estrangeiros, ora almejando construir um teatro local com base em raízes culturais amazônicas.

O contexto político que se estabeleceu pós1964 engendrou novas perspectivas dos artistas, fazendo com que alguns segmentos procurassem produzir uma arte mais engajada aos anseios e lutas do povo. Alguns críticos, como Ridenti (2000), já se debruçaram sobre o tema, tendo como ponto de partida os movimentos culturais brasileiros ligados à esquerda, que a partir dos anos 1960 procuraram produzir suas obras como lugar de resistência.

Ridenti (2000) chama atenção para o fato de os

1 Nesse contexto, as formas teatrais que trabalhamos são as ligadas ao chamado ciclo amador ou aquele que não está atrelado ao que no Pará se convencionou chamar de teatro popular. Salles (1994) define essas formas populares de acordo com um calendário festivo-cristão que perpassa do Natal ao Círio de Nazaré (festa católica tradicional na Amazônia): Pastorinha, Paixão de Cristo, Pássaro Junino, Boi Bumbá, e Teatro Nazareno. 
artistas brasileiros de esquerda produzirem obras de arte de resistência, e defende a tese de que havia neles um espírito revolucionário, que se estruturava, segundo o autor, em ideologias românticas, contra o grande capital. Dessa maneira, os artistas lutavam por uma cultura na qual as raízes das tradições populares fossem o epicentro de toda movimentação contra as classes dirigentes e conservadoras:

Havia grupos mais românticos que outros, mas todos respiravam e ajudavam a produzir a atmosfera cultural e política do período, impregnada pelas ideias de povo, libertação e identidade nacional - ideias que já vinham de longe na cultura brasileira, mas traziam especialmente a partir dos anos 50 a novidade de serem mesclados com influências de esquerda, comunistas ou trabalhistas. O romantismo de esquerda não era uma simples volta ao passado, mas também modernizador. Ele buscava no passado elementos para a construção da utopia do futuro. Não era, pois, um romantismo no sentido da perspectiva anticapitalista prisioneira do passado, geradora de uma utopia irrealizável na prática. Tratava-se de romantismo, sim, mas revolucionário (RIDENTI, 2000, p. 25).

Esse sentimento de brasilidade, no teatro, começou a ter novos sentidos a partir dos anos 50 , intensificado nas décadas seguintes, impulsionado pelas novas conjunturas socioculturais estabelecidas. A necessidade de colocar a cultura brasileira nos palcos, por meio de personagens que representavam a essência e a alma do homem do povo ganhou muitas tintas. Guarnieri, em 1958, encenou Eles não Usam Black-tie, destacando os conflitos dos operários, em face às opressões da cultura liberal. Posteriormente, o teatro brasileiro produzido no eixo Rio - São Paulo presenciou diversos movimentos em prol desta nacionalização temática tanto na dramaturgia, quanto em espetáculos que procuravam buscar as raízes do país. Ridenti (2005) destaca que:

Aquestão da identidade nacional e política do povo brasileiro estava recolocada, buscava-se ao mesmo tempo recuperar suas raízes e romper com o subdesenvolvimento, o que não deixa de ser um desdobramento à es- querda da chamada era Vargas, propositora do desenvolvimento nacional com base na intervenção do Estado (RIDENTI, 2005, p. 84).

O autor esclarece que o nacionalismo na política e na cultura/arte brasileira dos anos 1960 e 70 não nasciam com o golpe de 1964, mas que havia um sentimento revolucionário, plantado e amadurecido desde o período Vargas. Nesse contexto, o teatro vivenciou alguns momentos em que essas conjunturas sociopolíticas de desenvolvimento, de modernidade e de transformações, não apenas na industrialização, estavam presentes na produção artística:

Nesse sentido, a estrutura de sentimento da brasilidade revolucionária não nasceu do combate à ditadura mas vinha de antes, forjada no período democrático entre 1946 e 1964, especialmente no governo Goulart, quando diversos artistas e intelectuais acreditavam estar na crista da onda da revolução brasileira em curso. A quebra de expectativa com o golpe de 1964 - ainda mais sem resistência - foi avassaladora também nos meios artísticos e intelectualizados, como atesta o artigo clássico de Roberto Schwarz, publicado pela primeira vez em 1970 na França (RIDENTI, 2005, p. 85).

No teatro brasileiro, percebe-se a reverberação da questão da identidade nacional em várias direções. Sejam nas políticas estatais para a transformação das artes cênicas, cobradas por seus agentes culturais, sejam nas obras escritas e encenadas que procuravam dar o protagonismo para as realidades brasileiras. Nesses movimentos, veem-se o diálogo entre as formas que até o momento se conheciam ou as vanguardas procuradas. Contudo, a partir da década de 1960, a alma nacional passou a ter significados construídos muitos através de como a esquerda brasileira entendia e defendia os conceitos de povo, nação, arte engajada a essas questões. São esses pontos, contextualizados na região amazônica, que se quer destacar nesse texto, principalmente na produção teatral. 
Teatro na Amazônia em tempos de ditadura: a cultura local como resistência política

A proposta que se defende nesse artigo, é buscar perceber a produção teatral amazônica dos anos 1960 e 70 como reflexo ou diálogo com a nova organização social estabelecida pelo golpe de 1964. Tendo o regionalismo como esse lugar de pensar o homem amazônico, sua história, suas práticas culturais, os artistas de teatro iniciaram um movimento cultural muito importante. Analisar esses processos nos ajuda a compreender porque aspectos da cultura local paraense (os defendidos por gerações anteriores ligadas ao modernismo de 1920, 30 e 40 que buscava as raízes da cultura amazônica como lugar de representação e (re) escrita da história $)^{2}$, renegada pelo movimento amador de teatro dos anos 40 e 50, passou a ser vista e representada como o lugar de criação e resistência para os fazedores de teatro a partir dos anos 60 .

A cidade de Belém vivenciou, nas décadas de 1940 e 50, uma cultura teatral produzida por artistas e intelectuais ligados ao movimento amador e de estudante, articulado, nacionalmente, por Paschoal Carlos Magno. Os amadores locais viam como símbolo de modernidade e de vanguarda as obras da tradição nacional e estrangeira, além de textos contemporâneos a sua época. Esses últimos tinham de ser inéditos nos palcos nacionais, porque, dessa maneira, eles cumpriam a lógica dos festivais nacionais organizados por Paschoal, segundo eles: de proporcionar o que de mais novo havia no teatro estrangeiro ou o que a juventude e a sociedade brasileira não conheciam ainda ${ }^{3}$. Este pensamento esteve presente, também, nas encenações promovidas pela recém-criada Escola de Teatro, em 1963, a primeira da região amazônica. Havia, para essa geração, a preocupação de educar o público local, através de obras que esse público não conhecia; refinar o gosto das plateias, porque acredi-

2 Sobre essa discussão ver Figueiredo (2012).

3 Sobre essas questões ver Bezerra (2016). tavam na força da tradição dramatúrgica, na história teatral ocidental, como o lugar para tais metas.

Contudo, em paralelo ou caminhando junto a esse movimento ligado à Escola de Teatro paraense, a partir dos anos 1960, percebem-se artistas, principalmente na dramaturgia, preocupados em criar obras que colocassem o homem amazônico no protagonismo cultural, ou seja, a ideia de uma identidade de um sujeito amazônico, paraense. Era necessário, portanto, falar da história da Amazônia, dos hábitos e costumes, para além do existente na produção popular ligada, à época, mais a ideia "folclorizante". Havia um desejo de se reescrever essa história, sempre contada pelo olhar das elites dominantes. Por isso, para trazer à cena teatral a cultura amazônica, existia a necessidade de partir de um lugar, e a escolha pelo povo oprimido, marginalizado, inviabilizado nos processos culturais da região foi o prisma escolhido ou privilegiado, por alguns artistas e grupos de teatro.

É justamente nesse ponto que se procura, aqui, chamar atenção, porque nos anos 60 , principalmente a partir do Centro Popular de Cultura - CPC e suas "filiais" regionais, percebe-se na produção cultural uma retomada dos princípios artísticos dos modernistas da década de 1920 e 30 . Era necessário falar, representar o homem, a cultura e a história da Amazônia, e essa postura, no teatro, em nossa análise, aliava-se ao movimento cultural que se opunha ao poder hegemônico e ditatorial, que buscava a internacionalização do país, a abertura ao neoliberalismo da época. Em diálogo com as ideias de Ridenti (2005), percebemos que as obras dessa época:

Revelam a emoção e a solidariedade dos autores com o sofrimento do próximo, a denúncia das condições de vida subumanas nas grandes cidades e, sobretudo, no campo. Enfoca-se especialmente o drama dos retirantes nordestinos. A questão do latifúndio e da reforma agrária é recorrente, em geral associada à conclamação ao povo brasileiro para realizar sua revolução, em sintonia com as lutas de povos pobres da América Latina e do Terceiro Mundo (RIDENTI, 2005, p. 87). 
É interessante destacar que os artistas de teatro, na Belém dos anos 60, começam a fazer esse movimento em direção ao regionalismo, contudo, inicialmente, entendiam como parâmetro para o regional a cultura nordestina, que ganhara força com obras como as de Ariano Suassuna, por exemplo. A escola de teatro da Universidade encenou, nessa década, algumas peças do escritor paraibano, como O Santo e a Porca (1966). A instituição produziria, ainda, na década seguinte, trabalhos como $A$ Incelença, de João Marinho; O Coronel de Macambira, de Joaquim Cardozo; entre outros. Portanto, os artistas locais manifestavam essas duas perspectivas para o regionalismo: a cultura teatral nordestina, embebida em suas tradições; e a Amazônia que começava a ganhar espaço nas obras de autores locais.

Independente desses dois entendimentos percebe-se que havia a busca pela arte que representasse o povo, suas tradições, suas culturas, a procura de uma brasilidade, de uma nacionalidade que reverberava para a identidade amazônica, no caso do teatro em Belém. Buscava-se o povo, os oprimidos, historicamente, porque, segundo Ridenti (2005, p. 87), "era a categoria de povo que, acima das classes, tendia a predominar nessa estrutura de sentimento: os pobres, seres humanos miseráveis, desumanizados, deserdados da terra". A tese que se defende, portanto, é que esse modo de produção artística refletia as discussões e o contexto sociopolítico da ditadura militar brasileira, principalmente os artistas que eram da esquerda ou tinham afinidade com ela. Para Ridenti (2005), o contexto internacional das revoluções socialistas do século $\mathrm{XX}$, principalmente a soviética, a chinesa e a cubana contribuíram para o ambiente do que ele chama de estrutura de sentimento, na cultura brasileira:

Elas teriam repercussão no Brasil, especialmente entre artistas e intelectuais, muitos do quais foram militantes de esquerda. Ademais, a estrutura de sentimento da brasilidade revolucionária não se dissociava de traços do romantismo revolucionário em escala internacional nos anos de 1960: a fusão entre vida pública e privada, a ânsia de viver o momento, a liberação sexual, a fruição da vida boêmia, o desejo de renovação, a aposta na ação em detrimento da teoria, os padrões irregulares de trabalho e a relativa pobreza de jovens artistas e intelectuais (RIDENTI, 2005, p. 90).

Defende-se que no teatro produzido na Amazônia dos anos 60 e 70 há a forte presença dessa estrutura de sentimento de brasilidade, o regionalismo surge como força motivadora para se produzir uma arte local, que tinha como meta pôr em destaque os sujeitos e as práticas culturais silenciadas pela arte que valorizava a cultura estrangeira, os padrões, os temas e as formas burguesas de cultura. Além disso, a ideia de regionalismo atrelada ao Nordeste começava a ser questionada por artistas da Amazônia. Isso fica exposto nas reflexões que Márcio Souza faz, quando narra e problematiza a história do movimento teatral manauara a partir do grupo que fez parte, o TESC (Teatro Experimental do Serviço Social do Comércio do Amazonas):

Percebemos, por exemplo, que não podíamos cair na armadilha de repetir o regionalismo nordestino, requerendo-o com uma nova embalagem. Ao examinarmos o processo amazônico, sentimos também a necessidade de escapar da tradição regionalista conforme os nordestinos tinham estabelecido, porque se tratava de uma forma de arte ainda inscrita dentro da manipulação ideológica da classe dominante daquela região. O regionalismo aparecia com um sabor muito conservador, e não queríamos mais trabalhar com aparências, ao contrário, nossa vontade era mergulhar nas culturas indígenas e na história da Amazônia, devolvendo ao público, no palco, de uma maneira crítica e liberta, aquilo que havia sido mistificado (SOUZA, 1984, p. 28-29).

Essas questões estão fortemente presentes nas produções teatrais amazônicas dos anos 60 e 70 , principalmente nos dois grandes centros urbanos da região: Belém e Manaus. Contudo, como destaca Souza (1984), buscava-se um regionalismo que não representasse o conservadorismo das elites, mas que fosse um lugar de problematizar os conflitos sociais existentes e, para isso, é necessário repensar a pró- 
pria história da Amazônia. Dessa maneira, os sujeitos oprimidos (indígenas, migrantes nordestinos, moradores das regiões periféricas e rurais) passaram a ter o protagonismo nas histórias escritas e encenadas ${ }^{4}$.

\section{Nazareno Tourinho: uma dramaturgia re- gional como lugar de resistência e resiliência}

A preocupação de Nazareno Tourinho em produzir uma arte engajada à questão de valorização da cultura regional surge desde o momento em que se lançou como dramaturgo na década de 1960. Em 1968, com outros artistas locais, funda o TABA (Teatro Adulto de Belém Adulta), um grupo que buscava a valorização regional de suas obras e de seus artistas. Em um manifesto ${ }^{5}$, eles apresentam as linhas gerais de seus pensamentos, posicionamentos e pretensões estéticas e políticas:

TABA significa Teatro Adulto de Belém Adulta, e isso significa que, em matéria de arte cênica, acreditamos na maioridade cultural desta cidade e tentaremos demonstrá-la. Tal empreendimento parece presunçoso, porém torna-se absolutamente necessário como sugestão para um movimento que dê início a uma dramaturgia inspirada em nossa realidade social e nossos costumes, nascida dos valores da terra, até então desprezados. Queremos um teatro paraense, autêntico e característico, que aborde temas paraenses com autores paraenses, diretores paraenses, atores paraenses, cenógrafos paraenses e tudo o mais também paraense. Queremos simplesmente porque achamos que podemos e devemos fazê-lo, não pre

4 Não iremos debater, nesse artigo, a relação entre os temas e as formas escolhidas pelos artistas amazônicos. Esse tema fica para uma próxima reflexão, contudo, é importante destacar que muitos procuraram debater as questões de opressão utilizando os gêneros tradicionais do teatro burguês, principalmente o drama.

5 Manifesto do TABA. Belém, 1968. O texto é assinado por Nazareno Tourinho e Cláudio Barradas (TOURINHO; BARRADAS, 1968. Documento eletrônico). Acervo do projeto de pesquisa Memórias da Dramaturgia Amazônica, coordenado por Bene Martins. tendendo com essa revolução depreciar o trabalho dos que pensam de outra maneira. Afinal, estamos no Pará (TOURINHO; BARRADAS, 1968. Documento eletrônico).

O excerto acima revela, em linhas gerais, a pretensão desse novo grupo, com ênfase na valorização dos aspectos regionais tanto na escrita dramatúrgica, quanto no trabalho dos fazedores teatrais. A produção textual para o teatro deveria versar sobre a realidade amazônica, paraense, por meio da representação dos costumes, dos aspectos da cultura local, sem criar, aparentemente, uma divergência às outras formas de produção teatral presentes na cidade. Contudo, na assertiva de Tourinho percebe-se um posicionamento político importante, principalmente no sentido do nome dado ao grupo, um teatro adulto, que lemos como maduro, consistente, para uma Belém adulta, preparada e ligada a uma tradição teatral. Em seguida, continua:

Criar um teatro nosso para ser visto entre nós e se possível apresentado fora daqui como testemunho de progresso é o grande sonho que procuramos materializar, com a ajuda de outros ou apenas com o sacrifício próprio. Um teatro sério e de cunho regional, preocupado com a beleza estética e a informação da verdade, um teatro de aspecto documental e de crítica construtiva, que divirta o povo e o eduque intelectualmente, um teatro livre em sua expressão formal e livre em suas intenções, sem qualquer vínculo de qualquer natureza com qualquer doutrina política mas com direito à opinião (TOURINHO; BARRADAS, 1968. Documento eletrônico).

As pontuações acima dialogam com a temática do texto Severa Romana (1968) $)^{6}$, principalmente no aspecto do caráter documental da obra de Nazareno Tourinho, ao retratar a condição de moradores da peri-

6 Essa peça foi premiada em 1968, pela Academia Paraense de Letras, encenada pela primeira vez em 1969, no Teatro da Paz, dirigida pelo próprio autor pelo grupo TABA. Sua primeira edição em livro foi realizada pela Universidade Federal do Pará em 1976; e em 2014 foi reeditada, fruto da pesquisa Memórias da Dramaturgia Amazônida: construção de acervo dramatúrgico, coordenado pela professora Bene Martins (UFPA). 
feria da capital paraense, migrantes nordestinos, que em situações precárias viviam as mazelas sociais e refletiam as relações de poder, no caso entre os personagens Pedro Cavalcante de Oliveira, marido de Severa Romana, soldado subalterno ao Cabo do Exército Antônio Ferreira dos Santos. A escolha desse tema se justifica pela preocupação em falar de problemas socioculturais dos sujeitos da região amazônica.

Esta peça é uma comédia.

Não sei se tecnicamente, literariamente, é lícito a um autor fazer comédia com um tema trágico. Eu fiz. Fiz porque minha intenção, com esta peça foi, acima de tudo, documentar de forma alegre e agradável a antiga vida suburbana de minha terra, com suas crenças ingênuas e poéticas, sua linguagem típica, suas superstições e seus velhos costumes que vão desaparecendo à sombra dos edifícios de concreto. Ao escrever esta comédia "sui generis" agi com a maior honestidade intelectual. Procedi uma rigorosa pesquisa a fim de apurar como de fato ocorreu a história de Severa Romana, que até muitos consideram "santa", e coloquei na peça todos os detalhes encontrados, estruturei mesmo o enredo de acordo com tais detalhes, fazendo concessões à literatura, o que não é bom para um autor teatral. Um minucioso relatório com os dados da pesquisa que fiz acha-se no arquivo da Academia Paraense de Letras e prova o que digo acima. Enfim, aí está a comédia, e eu fiz porque o povo que amo e para quem escrevo ao assisti-la riu durante quase duas horas identificando-se com 0 passado ainda não esquecido, num reencontro cheio de ternura (TOURINHO, 2014, p. 113).

As considerações descritas acima pelo autor da obra revelam alguns pontos importantes para entender a escolha pelos subalternos, pelas tradições paraenses presentes na periferia de Belém. Ao desenvolver uma pesquisa documental sobre a história de Severa Romana, uma migrante que fora assassinada em 1900, em defesa de sua honra, Tourinho se dividiu entre o mito (considerada por muitos como uma Santa e cultuada pela população local, que fazem seus pedidos na sepultura localizada em um dos mais tradicionais cemitérios de Belém) e a pes- soa histórica. Contudo, nota-se que o enredo construído levou em conta a honra da mulher, que para se ver livre dos assédios de Antônio Ferreira dos Santos, chefe de seu esposo, enfrenta-o em diversos momentos, mas seu algoz a assassina quando é rejeitado e tenta estuprá-la, no nono mês de gravidez.

Tourinho destaca que escolheu o gênero comédia para falar de um tema trágico, porque se preocupava com a recepção do público. As escolhas do autor revelam que mesmo ao colocar no centro da ação de sua obra os conflitos de personagens periféricos, e como protagonista uma mulher, a abordagem não aprofunda a crítica ao pensamento patriarcal do qual as mulheres são vítimas; nem tampouco os conflitos de classe entre Antônio Ferreira dos Santos e Pedro Cavalcante de Oliveira. Além disso, as outras personagens femininas presentes na obra, Joana Maria Gadelha, hospedeira do casal, descrita com idade de 50 anos e parteira, e a Vizinha, com 70 anos, preta, não são desenvolvidas de maneira a levantar questões étnicas e outros temas que atravessam a representatividade desses sujeitos.

O dramaturgo escolhe a comicidade para trabalhar a personagem Vizinha, sem identidade, diferentemente de outras personagens que têm nome e sobrenome. Essa mulher, preta, conhecedora e praticante da medicina popular, conhecida como benzedeira ou feiticeira, aparece como aquela que orienta em questões de espiritualidade, muito presente na Amazônia. O cômico trabalhado é para gerar o riso, riso esse construído em cima dos estereótipos de personagens que revelam a representação daqueles que possuem tais comportamentos. Contudo, o dramaturgo, mesmo buscando construir uma obra crítica, ao colocar em sua obra uma personagem subalterna, não entra no debate da negritude, por exemplo.

Essa necessidade em mostrar que as mazelas sociais, os sistemas de opressão presentes no Brasil são históricos revela a preocupação de artistas engajados com as questões de sua época. Veem-se na obra de Nazareno Tourinho os temas recorrentes nas artes brasileiras desse momento. Na última parte do manifesto do TABA, os autores falam de 
um outro texto de Tourinho, que estreou a trajetória do grupo, e, em especial, da relação com os princípios de uma arte voltada para a realidade local ${ }^{7}$ :

Estrearemos no próximo mês com a peça Lei É Lei E Está Acabado ${ }^{8}$, obra que talvez os puritanos considerem imoral pelo fato de enfocar o drama e uma prostituta, que os radicais talvez julguem agressiva porque se não despeita a Polícia satiriza o procedimento de um policial, e que talvez os conservadores interpretem como perigosa porque fotografa a tragédia de um mendigo que morreu de fome na mais luxuosa avenida de nossa capital. Para os que assinam o presente manifesto, no entanto, assumindo inteira responsabilidade pela existência e atividades do TABA, Lei é Lei e está acabado é apenas uma obra digna de ser encenada para um público digno de assisti-la. Uma obra importante, porque ligada à linha de vanguarda do teatro moderno, e sobretudo importante porque produzida totalmente por nós mesmos, paraenses papa-chibés sem nenhuma pretensão de superioridade, mas, igualmente, sem nenhum complexo de inferioridade (TOURINHO; BARRADAS, 1968. Documento eletrônico).

Essa leitura sobre o trabalho com a cultura amazônica na arte teatral em Belém, nas décadas de 1960 e 70, revela que o regionalismo não é apenas uma escolha pelos hábitos locais, como uma espécie de ufanismo. Ao contrário, foi visto como o lugar de resistência dos artistas de teatro aos processos socioculturais gerados pela ditadura militar. Espaço de resistência, de militância, de denúncia e reflexão sobre os processos históricos de dominação e exploração da Amazônia, de suas riquezas, de seu povo.

A escolha em usar o teatro como lugar de resistência contra as opressões do sistema político da ditadura "revela sua inserção no eixo político-cultural de esquerda dos anos 60: a questão da identidade nacional e do caráter do povo brasileiro, com o qual os intelectuais e artistas buscavam

7 Apeça estreou nos palcos paraenses em 28 de outubro de 1968. Teve no elenco Cláudio Barradas, Antônio Lira, Maria Goretti e Homerval Thompson; cenários de Dalcyr Braga.

8 Bezerra (2013) apresenta uma análise dessa obra. identificar-se" (RIDENTI, 2000, p. 189). Falar de uma arte regional na segunda metade do século $X X$, na Amazônia paraense, é perceber as conexões que artistas de teatro estabeleceram com seu tempo presente. Momento em que o poder executivo brasileiro e os interesses das elites nacionais criavam planos para o desenvolvimento da Amazônia, por meio de projetos que exploravam o potencial energético e mineral do Pará, por exemplo.

Essas questões são evidentes em muitas obras teatrais escritas e encenadas por artistas paraenses nos palcos de Belém e de outras cidades brasileiras, porque esse momento foi de profunda produção e circulação dos grupos locais pelo país, seja em festivais promovidos pelas federações amadoras estaduais, seja pelos projetos do governo federal, como o Mambembão. Analisar o regionalismo no teatro produzido na Amazônia, nos anos 1960-70, é abrir um leque de possibilidades para se compreender os processos poéticos e políticos de uma geração de artistas de teatro da Amazônia paraense.

\section{Referências}

BEZERRA, José Denis de Oliveira. Lei é lei e está acabado: recepção do texto dramático de $\mathrm{Na}$ zareno Tourinho. In: FARES, Josebel Akel; RODRIGUES, Venize Nazaré Ramos (Org.). Sentidos da cultura. Belém: EDUEPA, 2013.

Vanguardismos e modernidades: cenas teatrais em Belém do Pará (1941-1968). Tese (Doutorado em História), Instituto de Filosofia e Ciência Humanas, Universidade Federal do Pará, 2016.

FIGUEIREDO, Aldrin Moura de. Os vândalos do apocalipse e outras histórias: arte e literatura no Pará dos anos 20. Belém: IAP, 2012.

RIDENTI, Marcelo. Em busca do povo brasileiro: artistas da revolução, do CPC à era da TV. Rio de Janeiro: Record, 2000. 
Artistas e intelectuais no Brasil pós-

1960. Tempo Social, 17(1), 81-110. São Paulo jun. 2005.

SALLES, Vicente. Épocas do Teatro no Grão-Pará ou Apresentação do Teatro de Época. Belém: UFPA, 1994.

SOUZA, Márcio. O palco verde. Rio de Janeiro: Marco Zero, 1984.

TOURINHO, Nazareno. Severa Romana. In: MARTINS, Bene (Org.). Peças teatrais de Nazareno Tourinho. Belém: CEJUP, 2014.

TOURINHO Nazareno; BARRADAS Cláudio. Manifesto do TABA. Projeto de pesquisa coordenado por Bene Martins. Belém, 1968.

Recebido: 28/11/2019

Aprovado: 30/05/2020 